\title{
Job satisfaction and turnover under the effect of person- organization fit in Albanian public organizations*
}

\author{
Mimoza Kasimati**
}

This paper presents the results of research conducted on public organizations employees for testing a model that relates person-organization fit, job satisfaction and turnover. Using a sample of 100 employees from 17 Albanian public organizations, this study brings out that there is a significant relationship between person-organization fit and job satisfaction in the public organizations in Albania. The implications of the study are discussed.

Dieser Artikel stellt die Resultate einer Untersuchung dar, deren Gegenstand war, an Angestellte von öffentlichen Organisationen ein Modell zu erproben, welches das Harmonieren der Person mit der Organisation mit der Arbeitszufriedenheit und der Fluktuation verknüpft. Durch die Benutzung einer Stichprobe von 100 Angestellten von 17 albanischen öffentlichen Organisationen, kommt diese Studie zu dem Ergebnis, dass es eine signifikante Verbindung zwischen dem Harmonieren einer Person mit der Organisation und der Arbeitszufriedenheit in öffentlichen Organisationen in Albanien gibt. Die Konsequenzen der Studie werden diskutiert.

Key Words: Person-organization fit; job satisfaction; turnover.

* Manuscript received: 20.05.2011, accepted 07.09.2011 (2 revisions)

** Mimoza Kasimati, $\mathrm{PhD}$, Associate professor of Organizational Behaviour, Tirana University. Main research areas: Questions of planned organizational change, organizational leadership and motivation. Corresponding address: moza_kasimati@yahoo.com 


\section{Rationale}

In the book Democracy and the Public Service, Mosher (1982) explains that Government decisions and behaviour are tremendously influential in our society; these decisions and behaviour are heavily influenced by non-elected administrative officials; the kinds of decisions and behaviours taken depend upon the officials' capabilities, orientations and values; these attributes depend upon their background, training, education etc.

After the communist period, public service was one of the things that had to be totally "invented" in Albania. Differently from other countries with a tradition of public service, that actually are facing certain heterogeneity and suffering a certain loosening of the ties with their traditions (Perry 2007), Albania is creating a public service from scratch. Coming from the experience of a partystate country, with an original way of understanding and practising, the terms public administration, public servant, civil servant, did not exist at all in the vocabulary of the Albanian language up to the beginning of the 1990's. In these last 20 years, a full set of adjustments has been necessary to build and bring together democracy with the public service, going from legislation to practical rules, form structures to mentality. The first Civil Service law in Albania was adopted in 1996, but it had a limited implementation due to the lack of institutions and detailed procedures. Although there has been a continuous advancement in the reform of public administration, the level of its achievements during the last period of 6-7 years is yet far off pre-established objectives (Shapo et al. 2008).

Public servant and civil servant are two terms that are sometimes used interchangeably. In the Western Balkans region, the term "public servant" has often a wider meaning than the term "civil servant". It is frequently used to denominate employees in all public services, including such specific specialised sectors like education, health protection, and the like. Two basic criteria are used to define civil servant (Respa 2009):

Where does the public servant work?

Or at which level of government is the public administration body positioned; and to which sector does this body belong.

What does the public servant do in his/her workplace?

Or, which level of responsibility best describes the work of the public servant, its institutional or statutory mandate; and what specific types of tasks is the public servant supposed to carry out.

Based on the combination of these four factors, although there are about 90.000 employees in the whole public sector in Albania, only 4000 out of them fall within the cathegory of civil servants, and only about 1400 civil servants out of 
the group of 4000 employees are centrally managed by the Department of Public Administration, established in 1999 (Shapo et al. 2008).

Civil servants are employed permanently (for life) and termination of employment can occur only in situations which are strictly specified by law. This service is considered to be the safest employer. As a rule, job security is significantly higher than in the private sector. This relative advantage offered by the legislation is assumed to constitute one of the main attractiveness factors of public administration jobs (Respa 2009). Other elements like: paid leave, stable working hours, strict observance of national holidays which are non-working days, equal treatment for women with regard to men, intergrated in the civil service legislation provide incentives to attract talent in the public administration in Albania.

Constructive efforts in the public sector are, at the same time, challenged by the development of the private market that is as young as the public service (there was no private sector at all before 1990 in Albania). Being without a tradition, and facing the competition with the private, the public service in Albania is challenged by a set of forces that are comparable with that of other countries, but differently from the others, the lack of the tradition makes this more challenging and with more opportunities at the same time.

The Albanian civil service is organised to be a mixed system, based mainly on the job/position, but including elements of career systems. The dominance of the position system can be observed in the recruitment criteria, the rules governing appraisal, transfer, etc. The actual law on civil service establishes an open system, allowing at the same time mobility and career development inside the system. But when it comes to career development instruments like lateral transfer and promotion, preference is rather given to attracting personnel from the private sector, who might in the current situation, presumably improve the quality of the civil service. A lateral transfer is given priority to fill in vacancies. But when the number of internal candidates is insufficient (at least four in-house candidates), the competition is opened to external candidates.

The uncertainty about the interpretation of the relevant provisions is another reason for the partially not existing application of the rules of career development (Shapo et al. 2008). The system does not allow promotion of two or three steps in the career scale (no fast track).

At the 2008 Regional Workshop on the attractiveness of Civil Service, it was briefly summarised in the Albanian presentation: "Seniority is more important than merit, and promotions are not clearly linked to performance. Career paths can be unclear and little emphasis is placed on staff development".

Besides the promotion to a higher rank/position, the international practice also aknowledges the possibility of promotion through the salary grid, linked to performance and appraisal results, combined with seniority. In the Albanian 
system, a civil servant cannot advance without obtaining a higher rank/position, which requires competition. This means that a civil servant cannot obtain a permanent increase of salary based on performance. Only annual (one-off) bonuses are awarded to the civil servants with the best marks in the annual appraisal, depending on budget. On the other side, performance appraisal is not yet playing the designated role as a human resources management instrument. Evaluators are still lacking the necessary skills and experience with regard to this task (Shapo et al. 2008).

Given the budgetary constraints and the expanded public services expected, the state faces a complex challenge of managing an effective specialised workforce. Government has created a special job classification and compensation system in an effort to attract qualified specialists, but as the system of position stimulates a higher inflow of professional candidates from outside the public administration, the urge to excel and seek professional advancement is not very high in those already in the system. We can say that "the links between performance and promotion are weak in Albania" (RESPA 2008).

Although the state has made important changes in job classification and compensation, average private sector salaries are still higher than the salaries that the government can offer. One young graduate may begin the first employment at the lowest possible level of payment no higher than about 30 thousand leke per month in the public service, while the basic salary in the private sector can be as much as 60 thousand leke per month.

One can arrive at the conclusion that although the public service is by law a safe place of employment, with some valuable incentives, being employed there is also a big challenge. It is not very "safe" in career possibilities, it does not remunerate in terms of effort required by the employee (everything at the end is a matter of budget availabilities), it is subject to subjectivity in performance evaluation and it is subject to change following political elections every four or eight years. Under the circumstances of high competition from the private sector in terms of high payment and fast career possibilities, employment by the public administration seems to be not a very lucky choice for young educated aspirants. Although in the public service they have a great chance of learning the 'ropes' of the profession, getting trained without payment (in Albania training of the public employmees is considered as a right), after a while, they find themselves with experience, but no real advancement opportunities, with a payment that is always constrained within rigid limits.

But still, the number of job applications is high compared to the job vacancy, and the turnover is low. The data shows that the average number of applicant per position is 5 applicants, where as for the positions at the level of Director the average is at around 4.5 (Shapo et al. 2008). According to an interview conducted by the author with the Head of the Department of Public Administration of Albania (DoPA/DAP in Albanian) for the purpose of this 
paper, the last four years data show a voluntary turnover not higher than 3-4\%. Probably the individual finds in public institution values that can not be found in private institutions, and probably the match of individual values with those of the institution makes the employment a satisfying experience that affects his decisions of employment and turnover. Probably the knowledge that he is working for something "big" and important gives individual reasons to be satisfied with being employed by the public administration, or the similarity of certain values and standards in perceiving the reality gives him the feeling of fitting in. So, what can be some non economic factors that link the individual with public organization and make him satisfied? Is this satisfaction that bonds individual with the public institution? Or is it the fit with the institution that makes the individual more satisfied and reluctant to leave ? Is the fit a question of age, or/and education, or/and tenure, or/and gender? Do these variables moderate the presumed effect of fit over satisfaction? Is turnover in public administration in Albania a matter of age, or education, or gender? Some of these questions were in the base of this inquiry and what was discovered, is broadly explained in the following parts of this paper.

\section{Literature review}

For the purpose of this study, a literature review was considered, with the main concern on: understanding what may be some reasons that may satisfy an educated employee beyond monetary incentives; understanding if there are reasons to believe that these satisfactory factors can be enough to keep someone employed for long; understanding what can be some ways/factors that make an individual feel like he belongs in an organization and doesn't want to leave as he is getting what is expecting (excluding here the monetary incentives). So the concepts of job satisfaction and person-organization fit were explored and some reasoning based on these concepts understanding was used to lay down the study hypotheses.

\section{Person-Organization Fit}

One of the reasons one likes to work for an organization is finding it a satisfying experience, among others, probably because the individual feels he fits within the organization. Person-organization fit is one of the most popular areas of research in the field of organizational behaviour and management. This domain of research concentrates on conceptualizing the levels of possible fit, the elements included in the fit, the ways of assessing the congruence, the effects it has on a number of variables within the organization, etc. Literature review reveals different levels of possible fit studied. Among them we can distinguish:

a) Congruence between the individual and organizational values. This value congruence reflects the similarity between an individual's personal values and the cultural value system of an organization. When individual's personal values are similar or aligned with organizational values, positive outcomes such as 
satisfaction, commitment, performance, career success, reduced stress, and lower turnover intentions are realized (e.g. C. Ostroff, et al. 2004). As values are components of organizational culture that guide an employee's behaviour (Schein 1992), and they are "fundamental and relatively enduring" (Chatman 1991), this individual-culture fit can be considered as an individual-organization fit, too.

b) Congruence between individual's goals and organization's goals (B. Schneider 1987).

c) Congruence between the individual preferences and needs and organizational systems and structures (Bretz et al. 1989; Cable/Judge 1994). In most of cases this conceptualization is used to explain person-vocation fit, but it is also used as an explanation for person-organization fit (Bretz/Judge 1994).

d) Congruence between the characteristics of individual personality and the organizational climate-labelled even as organizational personality (Burke/Deszca 1982).

It is not easy to differentiate among these different fit perspectives.

Kristof (1996) defines person-organization fit as the compatibility between people and organizations that occurs when: (a) at least one entity provides what the other needs, or (b) they share similar fundamental characteristics, or (c) both. As such, it can be spoken about supplementary and/or complementary congruence. Supplementary congruence is achieved when the fundamental characteristics of an individual and those of the organization are similar to each other, i.e. when personality, values, goals, and attitudes of the individual are related with the culture, climate, values, goals and norms of the organization. Complementary congruence is achieved when the characteristics of individuals and organizations add something that is missing to make each other whole (Kristof 1996; Muchinsky/Monahan 1987). For example, from a supplementary standpoint, congruence is achieved when organizations attract individuals who have similar goals and values, whereas from a complementary standpoint, congruence is achieved when the unmet needs of individuals are satisfied by the resources and tasks that are provided within organization. In either case, there is strong evidence that person-organization fit has a positive benefit on a range of employee attitudes and behaviors, particularly job satisfaction and turnover intentions (Bretz/Judge 1994; Kristof 1996, Kristof-Brown et al. 2005; Vancouver/Schmitt 1991).

Scholars have found that as the congruence between individuals and organizations increase, employees become more satisfied and less likely to leave their jobs (Boxx et al. 1991; Cable/DeRue 2002; Lovelace/Rosen, 1996; Silverthorne 2004; Sims/Kroeck 1994; Westerman/Cyr 2004).

Based on some facts presented above, there is some reason to believe that probably the low turnover in Albanian Public Administration is a result of 
supplementary or complementary congruence of the individual employed with this organization.

\section{Job satisfaction}

Job satisfaction essentially reflects the extent to which an individual likes his job. Formally defined, job satisfaction is an affective or emotional response toward various facets of one's job. Herzberg found that people are motivated when their needs for achievement, recognition, stimulating work, and advancement are satisfied. When an employee has the opportunity to experience achievement, recognition, stimulating work, responsibility and advancement, he feels an intrinsic motivation (Hackman/Oldham 1976). Research overwhelmingly demonstrates a moderately strong relationship between these job characteristics and satisfaction (Ambrose/Kulik 1999).

One early debate in the public administration literature centred on whether public employees were satisfied with the characteristics of public organizations (DeSantis/Durst 1996; Steel/Warner 1990). Some believed the bureaucratic nature of public organizations coupled with low salary levels inhibited high levels of job satisfaction among public employees. Contrary to these expectations, many researchers found job satisfaction to be high among public employees at all levels of government, whereas other studies reached an opposite conclusion (Bright 2008). The work conditions found to be the most influential on the job satisfaction and turnover intentions of public employees were the intrinsic non-monetary characteristics of their work, such as good social relationships with co-workers and supervisors, promotion opportunities, professional development opportunities, and participatory management strategies (Borzaga/Tortia 2006; DeLeon/Taher 1996; Ellickson 2002; Emmert/Taher 1992; Kim 2002, 2004; Wright/Davis 2003).

\section{Person-organization fit and job satisfaction}

Causes of job satisfaction are broadly explained by five predominant models (Brief). They are need fulfilment, discrepancies, value attainment, equity, and dispositional/genetic components. In brief, we can say the need fulfilment model proposes that satisfaction is determined by the extent to which characteristics of a job allow an individual to fulfil his needs. The unmet needs can affect satisfaction and turnover (Karr 1999). Although need fulfilment models generated controversy, it is generally accepted that need fulfilment is correlated with job satisfaction (Stone 1992). The discrepancies models propose that satisfaction is the result of difference between what an individual expects to receive from a job, such as good pay, promotional opportunities, and what he actually receives. Studies have revealed that met expectations are significantly related to job satisfaction (Wanous, et al. 1992). The value attainment model presents the idea that satisfaction results from the perception that a job allows for fulfilment of an individual's important work values (Locke 1984). In 
general, research consistently supports the prediction that value fulfilment is positively related to job satisfaction (Chatzky 2005). The equity model considers satisfaction as a function of how fairly an individual is treated at work. Employee's perceptions of being treated fairly at work are related to overall job satisfaction (Cohen-Charash/Spector 2001). The genetic model implies that stable individual differences are as important in explaining job satisfaction as are characteristics of the work environment.

Considering all the models of job satisfaction, and the different levels of individual -organization congruence commented above, we can suppose a strong relation among these two variables. The relation is materialized either in supplementary, or complementary, or both ways.

First study hypothesis: Person-organization fit appears to be a very important cause of the job satisfaction As the Person-organization fit literature strongly suggests, individuals who are compatible with the characteristics of their organizations will have higher job satisfaction when compared with individuals who are less compatible. There are many kinds of public organizations with different missions, goals, cultures, resources, and job tasks. Similarly, public employees have different characteristics from each other.

Hypothesis 1: Person-organization fit is significantly related to job satisfaction. As the compatibility between employees and organizations increase, their job satisfaction will increase.

\section{Job satisfaction, person-organization fit and turnover intentions}

Job satisfaction and turnover intentions are reflections of the outlook that employees have about their employment. This outlook is influenced by the degree to which employees' salient needs are satisfied by their work (Bright 2008). Employees display higher levels of job satisfaction, and subsequently lower turnover intentions, when the characteristics of their working environment satisfy their needs (Bright 2008).

Schneider (1987) includes turnover as a long term outcome attributed to P-O fit. Individuals with lower levels of value congruence with their organizations are more likely to leave their organizations than those of higher congruence levels (Chatman 1991; O'Reilly et al. 1991). O'Reilly's analysis (1991) indicated that value congruence was a significant determinant of actual employee turnover within two years of initial assessment of fit. Chatman (1991) reported that levels of value congruence measured both at entry and after one year of employment and socialization significantly predicted turnover. Utilizing multiple conceptualizations of person-organization fit, Bretz and Judge (1994) found that person-organization fit had a strong direct effect on organizational tenure.

Although scholars found public employees to have acceptable levels of job satisfaction, burnout was found to be a major threat in public organizations 
(Bright 2008). There is evidence that tenure is negatively related to the job satisfaction of public employees (Kamdron 2005; Naff/Crum 1999). In other words, the longer employees worked in public organizations, their job satisfaction decreased. Similarly, other studies have found burnout and exhaustion to be two of the most cited reasons individuals left public sector jobs (Kim 2004; Samantrai 1992).

Second study hypothesis: Person-organization fit appears to be a very important cause of the turnover intentions. As the person-organization fit literature strongly suggests, individuals who are compatible with the characteristics of their organizations will have higher job satisfaction and lower turnover intentions when compared with individuals who are less compatible.

Hypothesis 2: Person-organization fit is significantly related to turnover intentions. As the compatibility between employees and organizations increase, their turnover intentions will decrease.

Deducing from what has been said so far, this was an effort to understand the relation among person-organization fit, job satisfaction and turnover intentions for the public servants in Albania. This relation was supposed to be moderated by some biographical characteristics like: age, tenure, level of education, and gender. The model used, is as in the figure 1.

\section{Methodology}

\section{Study settings}

100 public employees took part in this study. The participants were randomly selected from the Ministry of Interior, the Ministry of Finance, the Ministry of Labour and Social Affairs, the Ministry of Education and Sciences, the Regional Education Directorate of Tirana, Durres and Shkoder, the University of Shkoder, the University of Durres, the Financial supervision authority, the Bank of Albania, the University Hospital Centre, the Central Elections Commission, the Albanian Electricity Power Corporation, the Parliament of Albania, the Tirana Library and the Albanian Army. These organizations were chosen to create a diverse sample of participants who represented a broad range of governmental occupations. As expected, the respondents represented a diverse mix of public sector occupations, some of which were: finance and budgeting specialists, specialist lawyers, HRM specialists, R\&D specialists, academic staff, medical doctors, maintenance staff and security guards. 
Figure 1. The conceptual model tested in this study

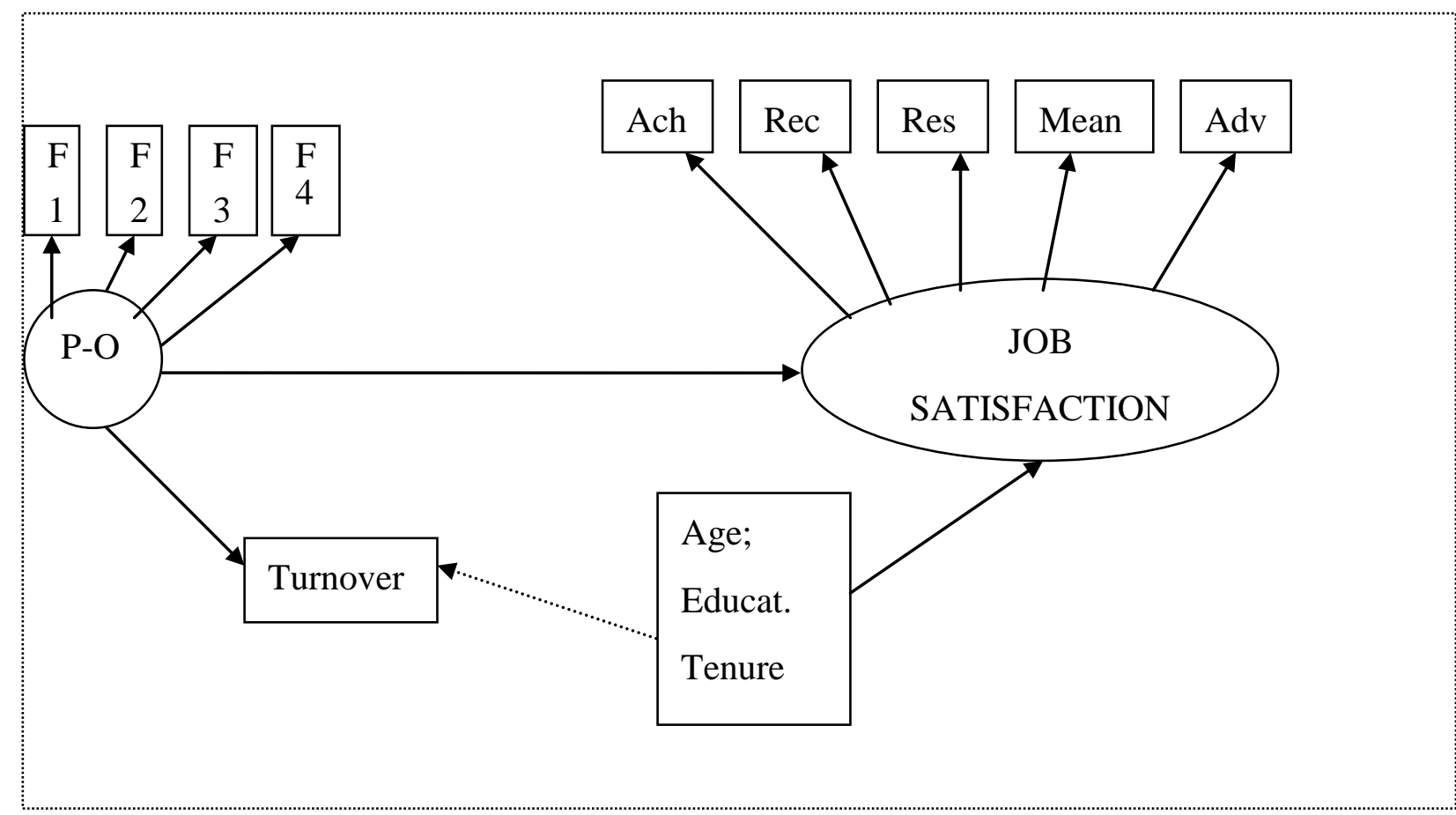

The respondents were also demographically diverse by their age, gender, and education. Table 1 makes a description of the control variables in the sample. There was no direct contact between the author and the respondents. As the research was not commissioned by the institutions observed, no identifying information was collected. As such, it was not possible to generate an accurate response rate for each participating organization. However, after reviewing the respondents' job titles, the author was confident that each participating organization was evenly represented.

Table 1. Survey sample control variables $(N=100)$

\begin{tabular}{|c|l|l|}
\hline & Frequency & Percentage \\
\hline Education level & & \\
High school diploma & 2 & 2 \\
Bachelor's degree & 51 & 51 \\
Master's degree & 44 & 44 \\
PhD & 3 & 3 \\
\hline Gender & & \\
Male & 33 & 33 \\
Female & 67 & 67 \\
\hline
\end{tabular}

Age average $=35.37$ years, tenure average in public sector $=10.47$ years 


\section{Person-organization fit}

There are different strategies that can be used to assess the fit, based on perceived fit, or on the assessed characteristics of the organization and the individual. Direct strategies assess such a fit by asking the respondents for their perceptions of their fit in their organizations. Indirect strategies, in contrast, assess fit by comparing separate assessments of the respondents' characteristics and the characteristics of their organizations (Kristof-Brown et al. 2005). Empirical research has shown that direct measures are stronger and better predictors of employee outcomes than indirect measures (Kristof-Brown et al. 2005; Verquer et al. 2003).

This study took a supplementary and direct approach to measuring the congruence between the respondents and their organizations. The participants were asked to indicate their agreement with the following four statements from 1 (strongly disagree) to 7 (strongly agree): My values and goals are very similar to the values and goals of my organization; I am not very comfortable within the culture of my organization (reverse scored); I feel a strong sense of belonging to my organization; and what this organization stands for is very important to me. These statements were developed from a review of existing research (Kristof 1996; O’Reilly/Chatman 1986).

\section{Job satisfaction}

This study used a multi-item scale to measure the job satisfaction of the respondents. This scale was developed from a review of the public administration job satisfaction literature. As discussed, existing research shows that the job satisfaction of public employees is mainly influenced by the intrinsic non-monetary characteristics of their work, such as advancement opportunities, professional development, and meaningful work (Borzaga/Tortia 2006; Deleon/Taher 1996; Ellickson 2002; Emmert/Taher 1992; Kim 2002; Wright/Davis 2003). The participants of this study were asked five questions about their satisfaction with opportunities for achievement, recognition, responsibility, meaningfulness, and advancement in their jobs (one for each). A seven scale measure was used for the answers, from 1(very dissatisfied) to 7 (very satisfied). The questions about Job satisfaction are as in the table 2.

The responses to these questions were used as five observed indicators of job satisfaction.

\section{Turnover intentions}

One question was used to measure turnover intentions. The respondents were asked to answer the following question using a scale from 1 (very unlikely) to 6 (very likely): Within the next 2 years, how likely are you to leave your current organization for a job in another organization? 
Table 2: Description of questionnaire questions

\begin{tabular}{|lr|}
\hline Person-organization fit & F1 \\
\hline 1. My values and goals are very similar to the values and goals of my organization. & F2 \\
\hline 2. I am not very comfortable within the culture of my organization (R). & F3 \\
\hline 3. I feel a strong sense of "belonging" to my organization. & F4 \\
\hline 4. It is very important for me what this organization makes for my country. & ACH \\
\hline Job satisfaction questions & REC \\
\hline 1. How satisfied are you with your opportunities for achievement? & RESP \\
\hline 2. How satisfied are you with your recognition opportunities? & MEAN \\
\hline 3. How satisfied are you with your level of responsibility on your job? & PROM \\
\hline 4. How satisfied are you with the meaningfulness of your job? & TURN \\
\hline 5. How satisfied are you with your advancement opportunities? & Turnover intentions \\
\hline $\begin{array}{l}\text { Within the next 2 years, how likely are you to leave } \\
\text { your current organization for a job in another organization? }\end{array}$ & \\
\hline
\end{tabular}

\section{Control variables}

Based on the supposition that job satisfaction and turnover intentions are somehow related with biographical characteristics of the individual, some control variables were used. These were: age, gender, education level, and years of public sector experience. The age of the respondents was measured using the open-ended question: When were you born? The current age was then calculated by subtracting the year of birth from the year 2009 which is the year of the study. The gender of the participants was collected with the direct multiplechoice question: What is your gender? The $0 / 1$ coding was used for that. The level of education of the participants was collected from the open question: What is the highest level of your education? These responses were coded from 1 (high school) to $4(\mathrm{PhD})$. The tenure in public sector was collected from the open question: For how many years have you been working in the public sector?

\section{Analysis process}

After the data collection process, the data were analyzed in two stages. First, the data were examined to ensure the normality. The data were found to be inacceptable. Only one questionnaire had no data on control variables. According to Curran, West, and Finch (1996), skewness ranges should be fewer than 2 and kurtosis ranges fewer than 7. As shown in Table 3, almost of the variables used in this study are between these suggested ranges. 
Table 3. Study variables

\begin{tabular}{|l|r|r|r|r|r|}
\hline & N & \multicolumn{1}{|c|}{ Mean } & $\begin{array}{c}\text { Std. } \\
\text { Deviation }\end{array}$ & Skewness & Kurtosis \\
\hline F1 & 100 & 5.31 & 1.426 & -0.715 & -0.055 \\
\hline F2 & 100 & 3.17 & 2.065 & 0.491 & -1.219 \\
\hline F3 & 100 & 5.52 & 1.598 & -1.021 & 0.195 \\
\hline F4 & 100 & 6.17 & 1.288 & -2.034 & 4.706 \\
\hline ACH & 100 & 4.91 & 1.590 & -0.435 & -0.536 \\
\hline REC & 100 & 5.07 & 1.695 & -0.658 & -0.578 \\
\hline RESP & 100 & 5.48 & 1.474 & -1.303 & 1.697 \\
\hline MEAN & 100 & 5.87 & 1.212 & -0.963 & 0.543 \\
\hline PROM & 100 & 4.66 & 1.695 & -0.465 & -0.703 \\
\hline TURN & 100 & 2.94 & 1.802 & 0.545 & -1.099 \\
\hline
\end{tabular}

Second, the data were analyzed using SPSS program. The structuring equation modelling should have been more appropriate, but the author lacked the ability to deepen analysis in this direction. Figure 1 displays the conceptual model that was tested in this study. This model tested the relationships among personorganization fit, job satisfaction, and the turnover intentions of the respondents. The results of this study are displayed in the following Tables and will be discussed later. Statistical significance was set at .001, two-tailed.

Table 4: Survey frequency responses to person-organization (personorganization) fit, job satisfaction, and turnover intention questions.

\begin{tabular}{|l|l|l|l|l|}
\hline & F1 & F2 & F3 & F4 \\
\hline P-O-Fit & Count & Count & Count & Count \\
\hline 1 Strongly disagree & 1 & 30 & 2 & 2 \\
\hline 2 Disagree & 3 & 22 & 4 & 1 \\
\hline 3 Somewhat disagree & 8 & 7 & 8 & 1 \\
\hline 4 Neutral & 15 & 10 & 10 & 5 \\
\hline 5 Somewhat agree & 21 & 11 & 14 & 14 \\
\hline 6 Agree & 29 & 13 & 26 & 19 \\
\hline 7 Strongly agree & 23 & 7 & 36 & 58 \\
\hline Total & $\mathbf{1 0 0}$ & $\mathbf{1 0 0}$ & $\mathbf{1 0 0}$ & $\mathbf{1 0 0}$ \\
\hline
\end{tabular}


Table 4: Continued

\begin{tabular}{|l|l|l|l|l|l|}
\hline & ACH & REC & RESP & MEAN & PROM \\
\hline Job-Satisfaction & Count & Count & Count & Count & Count \\
\hline 1 Very dissatisfied & 3 & 3 & 4 & 0 & 5 \\
\hline 2 Dissatisfied & 3 & 6 & 1 & 2 & 7 \\
\hline 3 Somewhat dissatisfied & 15 & 12 & 4 & 1 & 15 \\
\hline 4 Neutral & 18 & 14 & 11 & 11 & 15 \\
\hline 5 Somewhat satisfied & 20 & 13 & 20 & 21 & 19 \\
\hline 6 Satisfied & 22 & 29 & 34 & 24 & 26 \\
\hline 7 Very satisfied & 19 & 23 & 26 & 41 & 13 \\
\hline Total & $\mathbf{1 0 0}$ & $\mathbf{1 0 0}$ & $\mathbf{1 0 0}$ & $\mathbf{1 0 0}$ & $\mathbf{1 0 0}$ \\
\hline
\end{tabular}

\begin{tabular}{|l|l|}
\hline TURN & Count \\
\hline 1 Very unlikely & 28 \\
\hline 2 Unlikely & 25 \\
\hline 3 Somewhat unlikely & 11 \\
\hline 4 Neutral & 13 \\
\hline 5 Somewhat likely & 7 \\
\hline 6 Very likely & 16 \\
\hline Total & $\mathbf{1 0 0}$ \\
\hline
\end{tabular}

Count and \% values are equivalent, as $N=100$.

\section{Study Findings}

\section{Description of the Survey Responses}

This study collected the respondents' level of person-organization fit, job satisfaction, and turnover intentions. It intended to understand the supposed relation among the Person-Organization fit and the satisfaction; as well as the relation among the person-organization fit and turnover in the public organization employees. Four control variables were used for their supposed modification effect. The results are summarized in Tables 5 through 11, and these results will be the focus of the following discussion.

The majority of the respondents suggested that they were congruent with their respective organizations. Each of the components of congruence considered, were significantly connected with the concept of fit. Values congruence (.816), the culture (.665), belongingness (.821) and liking the contribution of the organization in the general welfare of the country (.770) all came out to very important components of the individual-organization fit. In total, these components explain $51 \%$ of the variance of this variable. 
Table 5: Person-organization fit (total variance explained)

\begin{tabular}{|c|c|c|c|c|c|c|}
\hline \multirow{2}{*}{ Component } & \multicolumn{3}{|c|}{ Initial eigenvalues } & \multicolumn{3}{|c|}{ Extraction sums of squared loadings } \\
\cline { 2 - 7 } & Total & $\%$ of Variance & $\begin{array}{c}\text { Cumulative } \\
\%\end{array}$ & Total & $\begin{array}{c}\% \text { of } \\
\text { Variance }\end{array}$ & $\begin{array}{c}\text { Cumulative } \\
\%\end{array}$ \\
\hline 1 & 2.044 & 51.099 & 51.099 & 2.044 & 51.099 & 51.099 \\
\hline 2 & .964 & 24.095 & 75.194 & & & \\
\hline 3 & .571 & 14.283 & 89.477 & & & \\
\hline 4 & .421 & 10.523 & 100.000 & & & \\
\hline
\end{tabular}

Extraction Method: Principal Component Analysis.

Table 6: Person-organization fit.

\begin{tabular}{|c|c|}
\hline & Component \\
\hline & 1 \\
\hline F1 & .816 \\
\hline F2 & -.335 \\
\hline F3 & .821 \\
\hline F4 & .770 \\
\hline
\end{tabular}

Component Matrix (a)

Extraction Method: Principal Component Analysis, a 1 components extracted.

The vast majority of the respondents (from 39\% to 65\%) appeared to have high levels of job satisfaction. The meaningfulness is the most appreciated element of job satisfaction. $65 \%$ of respondents were satisfied or highly satisfied by this element. Even the possibility of perceiving responsibility doing the job makes $60 \%$ of the respondents satisfied or highly satisfied. Following on from that, comes the recognition (52\%) and achievement (41\%). Only the perceived promotion possibility has a lower level of respondents satisfied or very satisfied (39\%). This probably is correlated with the open career systems applied in the Albanian Public Administration.

Table 7: Job satisfaction

\begin{tabular}{|c|c|}
\hline & Component \\
\hline & 1 \\
\hline ACH & .805 \\
\hline REC & .828 \\
\hline RESP & .802 \\
\hline MEAN & .652 \\
\hline PROM & .676 \\
\hline
\end{tabular}

Component Matrix (a)

Extraction Method: Principal Component Analysis, a 1 components extracted. 
The Job satisfaction concept is $57 \%$ explained by the intrinsic non-monetary characteristics of the respondents work, such as achievement, recognition, responsibility, meaningfulness and advancement.

Table 8. Job satisfaction (total variance explained)

\begin{tabular}{|c|c|c|c|c|c|c|}
\hline Component & \multicolumn{3}{|c|}{ Initial Eigenvalues } & \multicolumn{3}{|c|}{ Extraction Sums of Squared Loadings } \\
\hline & Total & $\begin{array}{c}\% \text { of } \\
\text { Variance }\end{array}$ & $\begin{array}{c}\text { Cumulative } \\
\%\end{array}$ & Total & $\begin{array}{c}\% \text { of } \\
\text { Variance }\end{array}$ & Cumulative \% \\
\hline 1 & 2.859 & 57.182 & 57.182 & 2.859 & 57.182 & 57.182 \\
\hline 2 & .981 & 19.616 & 76.798 & & & \\
\hline 3 & .570 & 11.399 & 88.197 & & & \\
\hline 4 & .325 & 6.497 & 94.694 & & & \\
\hline 5 & .265 & 5.306 & 100.000 & & & \\
\hline
\end{tabular}

Extraction Method: Principal Component Analysis.

Finally, $64 \%$ of the respondents suggested that they had few intentions of leaving their organizations. The author believes the results over turnover may have a more complex interpretation under the present supply-demand conditions of the labour market.

It is important to note that none of the control variables was significantly related to the study variables.

Table 9: Correlation coefficients of control variables

\begin{tabular}{|c|c|c|}
\hline & Correlation with SAT & Correlation with TURN \\
\hline AGE & 0.00 & -0.085 \\
\hline GENDER & -0.046 & -0.14 \\
\hline EDUCATION & 0.01 & 0.15 \\
\hline TENURE & 0.13 & 0.06 \\
\hline
\end{tabular}

The first hypothesis focussed on the relationship between person-organization fit and the job satisfaction of the respondents. It was hypothesized that personorganization fit would be significantly related to the job satisfaction of public employees. This hypothesis was strongly supported by the findings of this study. Person-organization fit was found to be significantly and positively related to the job satisfaction of the respondents. The respondents that reported being highly congruent with their organizations also reported being significantly more satisfied with their jobs when compared with their counterparts. It is also important to highlight the magnitude of the relationship between personorganization fit and job satisfaction. That is, person-organization fit accounted for most of the variance in job satisfaction (0.7). This finding suggests that 
person-organization fit was the most important predictor of job satisfaction in this study.

Table 10: Correlation between person-organization fit and job satisfaction.

\begin{tabular}{|c|c|c|c|}
\hline & & $\begin{array}{c}\text { REGR } \\
\text { factor score } \\
1 \text { for } \\
\text { analysis } 1\end{array}$ & $\begin{array}{c}\text { REGR } \\
\text { factor score } \\
1 \text { for } \\
\text { analysis } 2\end{array}$ \\
\hline \multirow{3}{*}{$\begin{array}{l}\text { REGR factor } \\
\text { score } 1 \text { for } \\
\text { analysis } 1\end{array}$} & $\begin{array}{c}\text { Pearson } \\
\text { Correlation }\end{array}$ & 1 & $.706(* *)$ \\
\hline & Sig. (2-tailed) & & .000 \\
\hline & $\mathrm{N}$ & 100 & 100 \\
\hline \multirow{3}{*}{$\begin{array}{l}\text { REGR factor } \\
\text { score } 1 \text { for } \\
\text { analysis } 2\end{array}$} & $\begin{array}{c}\text { Pearson } \\
\text { Correlation }\end{array}$ & $.706(* *)$ & 1 \\
\hline & Sig. (2-tailed) & .000 & \\
\hline & $\mathrm{N}$ & 100 & 100 \\
\hline
\end{tabular}

** Correlation is significant at the 0.01 level (2-tailed).

The second hypothesis focussed on the relationship between person-organization fit and the turnover intentions of the respondents. It was hypothesized that person-organization fit would be significantly related to the turnover intentions of the respondents. The findings of this study do not support this hypothesis in a significant level (-0.3).

Table 11: Correlation between person-organization fit and turnover intentions

\begin{tabular}{|c|c|c|c|}
\hline & & $\begin{array}{l}\text { REGR factor } \\
\text { score } 1 \text { for } \\
\text { analysis } 1\end{array}$ & TURN \\
\hline \multirow[t]{3}{*}{$\begin{array}{l}\text { REGR factor } \\
\text { score } 1 \text { for } \\
\text { analysis } 1\end{array}$} & $\begin{array}{c}\text { Pearson } \\
\text { Correlation }\end{array}$ & 1 & $-.320(* *)$ \\
\hline & Sig. (2-tailed) & & .001 \\
\hline & $\mathrm{N}$ & 100 & 100 \\
\hline \multirow[t]{3}{*}{ TURN } & $\begin{array}{l}\text { Pearson } \\
\text { Correlation }\end{array}$ & $-.320(* *)$ & 1 \\
\hline & Sig. (2-tailed) & .001 & \\
\hline & $\mathrm{N}$ & 100 & 100 \\
\hline
\end{tabular}

** Correlation is significant at the 0.01 level (2-tailed).

\section{Discussion of empirical findings}

The purpose of this study was to explore the extent to which person-organization fit is related with job satisfaction and the turnover intentions of public employees in Albanian environment. A possible correlation was assumed, with person-organization fit as a possible cause of job satisfaction and turnover 
intentions. Person-organization fit was evaluated by the self reporting of the perceptions held by public employees. It came out that only $51 \%$ of the "fit" was explained by the questions included.

As was stated above, a supplementary congruence was assumed. What about a possible complementary congruence? Although public administration is now performing in the environment of the Albanian market economy, it follows the well known way of a bureaucracy, in the classical meaning of the word. Excluding the political factor that interferes with employment once in four or eight years following the political changes in Government, the public administration is a more stable place to work. One of the values one may seek is that of continuity. But no item addressed this in the questionnaire (Part of person-organization fit). Also some important facets of one's job within public organization institutions like achievement, recognition, responsibility, etc were not addressed. The sense of responsibility was evaluated in the out-of-theinstitution way of thinking (It is very important for me what this organization makes for my country) but not evaluated the feeling of being responsible within the institution, with colleagues and within organizational structures. These facets of one's job were only considered as factors of job satisfaction (Achievement, Recognition, Responsibility, Meaning, and Advancement). Under this construction, the correlation person-organization and job satisfaction, is considerable (0.7), but probably the cause-effect direction is not as clear as it was thought in the beginning.

Job satisfaction on the other side was considered as a construct of perceptions about some non-monetary benefits one may have from the job. The vast majority of the respondents (from 39\% to 65\%) appeared to have high levels of job satisfaction. The meaningfulness is the most appreciated element of job satisfaction. $65 \%$ of respondents were satisfied or highly satisfied by this element. Even the possibility of perceiving responsibility doing the job makes $60 \%$ of the respondents satisfied or highly satisfied. Then there follows recognition with $52 \%$ and achievement with $41 \%$. Only the perceived promotion possibilities have a lower level of respondents satisfied or very satisfied (39\%). This probably is correlated with the mixed career systems applied in the Albanian Public Administration (Kasimati/Mitllari 2009), as well as non quantified effect of political interference in decision making. In year 2008, there were 307 individuals employed; only two of them were from inside the institution (DAP/DoPA, 2009).

These five benefits / components of job satisfaction explain 57\% of the variance of this variable. There are of course other non-monetary and monetary aspects of one's job that make it satisfactory, especially in the actual situation of the labour market in Albania. Although not published, informality is calculated to cover up to $20 \%$ of the country's GDP. Although not included in this data, this informality is certainly to be found in the labour market as well. Individuals 
employed in the private market suffer this informality in many ways: social insurance payment under the legal provision level; the individual is forced to fill the labour week with many small works out of the field of specialization, thanks to the small company that can't fully use a specialist, but has to keep in the payroll; the employment is never secure, as the culture within the companies, for many reasons, is not consolidated yet, but mostly because of the mentality of the private Albanian companies who have not yet understood the importance of regulations within organization.

In public administration, payment may be lower, but there are not so many other worries. Institutional performance is regulated by law. Public organizations are much more matured than most of the Albanian small and medium private companies, and things are more settled. In these organizations, the individual is granted any necessary time to learn, and a lot of effort and money are spent every year by the Government for training, and improvement in procedures. Only in 2009 there were spent about 100 thousand EUR on training (ITAP/TIPA 2010).

These circumstances might account for the $43 \%$ of the unexplained variance of job satisfaction. Not only this, but some of these factors may be reasons for a perceived better person-organization fit, probably in the complementary side of the congruence.

There was assumed a possible cause-effect relation between person-organization fit and turnover intention. Although $64 \%$ of the respondents suggested that they had few intentions of leaving their organizations, the relation is not significant $(-0.3)$, i.e. they may have no intentions to move on, but this doesn't come about because they fit well within the public administration, but for other reasons which were not included in the study. The author believes the results in turnover may have a more complex interpretation under the present supply-demand conditions of the labour market in Albania.

In general, we may say based on the results of this study, that there is a considerable relationship between person-organization fit of the public employee and his/her job satisfaction, in terms specified here. There is no significant relation of person-organization fit of the public employee and his/her intention to leave the public administration, in terms specified here. For this sample, this is true independently from age, education, tenure, or gender.

It appears not normal and is not based theoretically the non relation of turnover intention and job satisfaction with the tenure in public administration for this sample.

\section{Conclusion}

Albania is a country committed to the objective of becoming a candidate country for membership of the European Union. In pursuit of this objective, one of the 
medium-term priorities is the reform of the administrative system towards standards that ensure an effective support for the adoption and for the implementation of the acquis communitare. The reinforcement of administrative capacities, as identified in the document of European Partnership with Albania (2007), is a key priority for the implementation of SAA.

As a matter of fact, in last ten years, Public Administration in Albania is following a way of reforms that intends to increase the efficiency of services. All the human resources are managed in the function of achieving the highest quality possible. The rules and regulations of recruitment and promotion are adjusted aiming at the inclusion of the most motivated individuals and development of organizational commitment (Shundi, 2002). The employee in this administration is promoted according to personal and group achievement, as well as according to demonstrated personal characteristics (Albanian Law of Civil Service 1999, and changes). The selection process intends the best fit of the individual with the public institution, for the benefit of both.

In this research, the fit of the individual (as an employee) with the public institution was assumed to be the influencer of his job satisfaction and turnover intentions. However, as it comes out from the results of this research, it is very possible that the job satisfaction and low turnover intentions of the public employees influenced their perceptions of fit. As a result, the findings of this study only suggest that a causal relationship exists among the study variables, while recognizing the possibility of two-direction relationships.

Based on this experience, and upon the knowledge that monetary incentives are only part of one individual's satisfaction at work, more effort has to be dedicated on the identification of job-related variables that affect retention of qualified individuals in the public administration. That was the primary goal of this study, but as the sample was not very high, extensive research is needed. It is also important to broaden the understanding of the public managers on the variety of subordinates' job expectations. Certain aspects of the concept of job satisfaction may be included in the public managers' soft skills training.

\section{References}

Albanian Law for Civil Service: Ligji Nr. 8549, date 11.11.1999 "Statusi Nepunesit Civil". http://www.pad.gov.al/legjislacione.html.

Ambrose, M. L., Kulik, C. T. (1999). Old Friends, New Faces: Motivation Research in the 1990s. Journal of Management, 25, 231-292.

Borzaga, C., \& Tortia, E. (2006). Worker motivations, job satisfaction, and loyalty in public and nonprofit social services. Nonprofit and Voluntary Sector Quarterly, 35, 225-248.

Boxx, R W., Odom, R. Y., \& Dunn, M.G. (1991) Organizational values and value congruency and their impact on satisfaction, commitment, and cohesion: An empirical examination within the public sector. Public Personnel Management, 20, 195-206. 
Bretz, R. D., \& Judge, T. A. (1994). Person-organization fit and the theory of work adjustment: Implications for satisfaction, tenure, and career success. Journal of Vocational Behavior, 44, 32-54.

Bretz, R.D., Asch, R.A., Dreher, G.F. (1989). Do people make the place? An examination of the attraction-selection-attrition hypothesis. Personnel Psychology, 42. 561-581.

Brief. Attitudes in and around Organizations.

Bright, L. (2008). Does Public Service Motivation Really Make a Difference on the Job Satisfaction and Turnover Intentions of Public Employees? The American Review of Public Administration. 38, 149-166.

Burke, R.J. Deszca, E. (1982). Preferred organizational climates of Type A individuals. Journal of Vocational Behavior, 21, 50-59.

Cable, D. M., DeRue, D. S., (2002). The convergent and discriminant validity of subjective fit perceptions. Journal of Applied Psychology, 87, 875-884.

Cable, D.M., Edwards, J. R. (2004). Complementary and Supplementary Fit: A Theoretical and Empirical Integration. Journal of Applied psychology, October 2004, 822-34.

Cable, D.M., Judge, T.A. (1994). Pay preferences and job search decisions: A personorganization fit perspective. Personnel Psychology, 47.317-348.

Chatman, J. (1991). Matching people and organizations: Selection and socialization in public accounting firms. Administrative Science Quarterly, 36, 459-484.

Chatzky, J. (2005). Making Time for Time Off. Money, April 2005, 48, 50.

Cohen-Charash, J. and Spector, P. E. (2001). The Role of Justice in Organizations: A MetaAnalysis. Organizational Behavior and Human decision Processes, November 2001, 278-321.

Curran, P. J.,West, S. G., \& Finch, J. F. (1996). The robustness of test statistics to nonnormality and specification error in confirmatory factor analysis. Psychological Methods, 1, 16-29.

DAP (2009). Raporti vjetor 2008. http://www.pad.gov.al/botime/Raportivjetor2008. Pg.7

DeLeon, L., \& Taher,W. (1996). Expectations and job satisfaction of local-government professionals. American Review of Public Administration, 26, 401-416.

DeSantis, V. S., \& Durst, S. L. (1996). Comparing job satisfaction among public and private sector employees. American Review of Public Administration, 26, 327-343.

Ellickson, M. C. (2002). Determinants of job satisfaction of municipal government employees. Public Personnel Management, 31, 343-359.

Emmert, M. A., \& Taher,W. A. (1992). Public sector professionals: The effects of public sector jobs on motivation, job satisfaction, and work involvement. American Review of Public Administration, 22, 37-49.

Hackman, J. R., Oldham, G. R. (1976). Motivation through the Design of Work: Test of a Theory. Organizational Behavior and Human Performance. 250-279.

ITAP (2010). Raporti vjetor 2009. www.itap.gov.al. P. 10

Kamdron, T. (2005). Work motivation and job satisfaction of Estonian higher officials. International Journal of Public Administration, 28, 1211-1240. 
Karr, A. S. (1999). Work-Week: A Special News Report about Life on the Job-and Trends Taking Shape There. The Wall Street Journal, June 29, 1999, p A1.

Kasimati, M., Mitllari, E. (2009). Career Systems in the Public and Private Sector in Albania. Similar Policies, Different problems. Buletini shkencor, Universiteti L.Gurakuqi, 3, 197-215.

Kim, S. (2002). Participative management and job satisfaction: Lessons for management leadership. Public Administration Review, 62, 231-241.

Kim, S. (2004). Factors affection state government information technology employee turnover intentions. American Review of Public Administration, 35, 137-156.

Kristof, A. L. (1996). Person-organization fit: An integrative review of its conceptualizations, measurement, and implications. Personnel Psychology, 49, 1-49.

Kristof-Brown, A. L., Zimmerman, R. D., \& Johnson, E. C. (2005). Consequences of individuals' fit at work: A meta-analysis of person-job, person-organization, persongroup, and person-supervisor fit. Personnel Psychology, 58(2), 281-342.

Lovelace, K., \& Rosen, B. (1996). Differences in achieving person-organization fit among diverse groups of managers. Journal of Management, 22, 703-723.

Munchinsky, P. M., \& Monahon, C. J. (1987). What is person-environment congruence? Supplementary verse complementary models of fit. Journal of Vocational Behavior, 31, 268-277.

Mosher, F. (1982). Democracy and the public service ( $2^{\text {nd }}$ edition). New York: Oxford University Press, 3.

Naff, K. C., \& Crum, J. (1999). Working for America: Does public service motivation make a difference? Review of Public Personnel Administration, 19, 5-15.

O’Reilly CA III, Chatman J, Caldwell DF. (1991). People and organizational culture: A profile comparison approach to assessing person-organization fit. Academy of Management Journal, 34. 487-516.

O'Reilly, C. A., \& Chatman, J. (1986). Organization commitment and psychological attachment: The influences of compliance, identification, internalization on pro-social behavior. Journal of Applied Psychology, 71, 492-499.

Ostroff, O., Shin, Y., \& Kinicki, A. (2008). Multiple Perspectives of Congruence and Employee Attitudes, Journal of Organizational Behavior.

Perry, J.L. (2007). Democracy and the New Public Service, The American Review of Public Administration, Vol 37,No. 1, March 2007, 3-16.

RESPA (Regional School of Public Administration, 2009). Attractiveness of Civil Service in the Western Balkans.

Samantrai, K. (1992). Factors in decision to leave: Retaining Social Workers with MSWs in public child welfare. Social Work, 37, 454-458.

Shapo, Zh., Hoxha, A., Roll, A. (2008). Civil Servants Legislation in Albania: An assessment of the Implementation. PHRD for Albania Development Policy Loan II.

Schein, E. (1992). Organizational culture and leadership. San Francisco:Jossey-Bass.

Schneider, B. (1987). The people make the place. Personnel Psychology, 40. 437-453. 
Shundi, A. (2002). Ligji mbi Sherbimin Civil. Published by Albanian Institute for Training the Public Administration (ITAP).

Silverthorne, C. (2004). The impact of organizational culture and person-organization fit on organizational commitment and job satisfaction in Taiwan. Leadership \& Organization Development Journal, 25, 592-599.

Sims, R. L., \& Kroeck, K. G. (1994). The influence of ethical fit on employee satisfaction, commitment and turnover. Journal of Business Ethics, 13, 939-948.

Stone, E. F. (1992). A critical Analysis of Social Information Processing Models of Job Perceptions and Job Attitudes, Job Satisfaction: How People Feel about Their Jobs and How It Affects Their Performance, 1992, 21-52.

Vancouver, J. B., \& Schmitt, N. W. (1991). An exploratory examination of personorganization fit: Organizational goal congruence. Personnel Psychology, 44, 33-352.

Verquer, M. L., Beehr, T. A., \& Wagner, S. H. (2003). A meta-analysis of relations between person organization fit and work attitudes. Journal of Vocational Behavior, 63. 473489.

Wanous, J. P., Poland, T. D., Premack, S.L, and Davis, K.S. (1992). The Effects of Met Expectations on Newcomer Attitudes and Behaviors: A Review and Meta-Analysis. Journal of applied psychology, June 1992, 288-97.

Westerman, J. W., \& Cyr, L. A. (2004). An integrative analysis of person-organization fit theories. International Journal of Selection and Assessment, 12, 252-261.

Wright, B. E., \& Davis, B. S. (2003). Job satisfaction in the public sector: The role of the work environment. American Review of Public Administration, 33, 70-90. 